\title{
Social life: \\ the paradox of multiple-queen colonies
}

\author{
Laurent Keller
}

$\mathrm{O}$ ver recent years, it has become clear that multiple-queen (polygynous) colonies are common in social insects, especially among ants, in which polygyny may be the predominant social structure ${ }^{1,2}$. The presence of several queens in the same colony raises two sets of issues with broad ecological and evolutionary implications. The first set relates to the factors favouring the evolution of such colonies. Increased queen number is generally associated with a decrease in individual reproductive output of queens (see Ref. 3), thus raising the question of why young queens join established colonies and why resident queens and workers accept them. These questions are much the same as those raised by the evolution of cooperative breeding and eusociality 3,4 . The second set of issues relates to the mechanisms maintaining reproductive altruism by workers when several queens contribute to reproduction. Colonies containing many queens are generally characterized by low within-nest genetic relatedness. Workers thus raise brood to which they are only distantly related, presenting a potential challenge to kin selection theory ${ }^{5-7}$.

Here, I discuss recent progress in our understanding of the selective forces leading to the evolution and maintenance of multiple-queen colonies. I focus on ants because they are the best-studied polygynous social insects and because they display large intra-and interspecific variation in queen number. I will not consider associations of queens during the period of colony foundation because such associations are generally transient and do not lead to long-term polygyny 2,8 .

\section{Why multiple queens?}

Mature ant colonies typically produce hundreds or thousands of new queens. Only a tiny fraction of them will ever succeed in founding a new colony ${ }^{9}$. Given that dispersal and independent colony founding are extremely risky, the best reproductive option for young queens generally is to enter an established colony, if they are accepted ${ }^{10}$. Thus, one intportant question concerns the conditions under which members of established monogynous colonies should accept additional queens, that is, become polygynous.

The first rigorous attempt to explain the evolution of polygyny on the edifice of kin selection ${ }^{11}$ was made by Peter Nonacs $^{5}$. In a set of models, he showed that two of the fac- tors selecting for acceptance of queens are (1) a high probability that nests will lose their queen and (2) a low queen lifespan compared to colony survivorship. In other words, members of a colony may benefit from re-accepting queens, possibly at the expense of their short-term inclusive fitness, when these new queens increase colony survival sufficiently to compensate for the short-term decrease in inclusive fitness. In accord with Nonacs' model, the lifespan of queens in monogynous ants tends to be much higher than that of queens from polygynous species ${ }^{12}$. However, as mentioned by Nonacs ${ }^{5}$ himself, it is not possible to determine whether shortlived queens favour polygyny or, altcrnatively, if polygyny selects for short-lived queens.

Another important factor selecting for polygyny is low success rate of dispersal and independent colony founding by young queens $4,8,10,13-16$. The lower the probability that young queens can successfully initiate a new colony on their own, the more frequently they should seek readoption into an established colony. This argument is akin to ecological constraints on independent breeding favouring communal breeding in birds, vertebrates and insects, 4 ,17-24. Furthermore, members of an established colony should also be more likely to reaccept some of the young queens they produce when these queens have a very low prospect of successful independent colony founding 25 .

It has been suggested that ecological constraints on independent colony founding favour polygyny in a number of ant species ${ }^{4,7-10,13,16}$. However, only two studies have specifically tested this hypothesis. Herbers ${ }^{14}$ showed that the degree of polygyny and the frequency of empty nest sites are inversely correlated across populations of Leptothorax longispinosus. Moreover, an experimental increase of nest sites resulted in a decrease in the mean number of queens per nest. In a comparative study of leptothoracine ants, Bourke and Heinze ${ }^{26}$ also found that polygyny was associated with nest-site limitation, cold climate and habitat patchiness, all factors that increase dispersal cost. Several other hypotheses have been put forward, but they do not seem to be of sufficient generality to account for the evolution of polygyny (Table 1; see also Refs 8,10,26).

Any force hypothesized to explain the evolution of polygyny must also explain the strong association that exists between the number of queens per colony and their 
Table 1. Hypotheses to account for the evolution of polygyny

\begin{tabular}{lll}
\hline Hypothesis & Evidence in favour & Possible counter-arguments
\end{tabular}

\section{Hypotheses postulating advantages to colony members}

High probability that nests will lose their queen 5,9 Polygyny decreases risk of colony extinction.

Short queen lifespan compared to colony survivorship 5 . Polygyny decreases risk of colony extinction.

Risky dispersa|13,14,26 (see text). Polygyny is adopted when new queens are unlikely to initiate successfully a colony on their own.
Some polygynous species have short-lived nests thus increasing the probability of queen loss.

Short lifespan of polygynous queens ${ }^{12}$.

Evidence from some species that polygyny is favoured by ecological constraints on independent

Polygynous colonies frequently reproduce by budding 12,28

Queens of some polygynous species have lost the ability to initiate a new colony without the help of workers.

Many leptothoracine ants are both polygynous and hosts to slavemaking ants ${ }^{44}$. defence against socially parasitic ants ${ }^{7,43,44}$

Intraspecific parasitism ${ }^{10}$. An increase in the number of related queens is selected when there is a high risk of foreign queens infiltrating the nest (the addition of unrelated queens having then a lower effect on the inclusive fitness of resident individuals).

increased genetic diversity ${ }^{46-48}$. Several benefits, such as expanded range of environmental conditions, that a colony can occupy, or higher resistance to parasites stemming from increased colony genetic diversity, have been proposed.

Reduced mortality of queens because of diploid male production under polygyny 51 . colony founding 14,26,42.
This argument seems correct.

Evidence that unrelated queens are accepted in colonies of $L$. acervorum ${ }^{15}$.

Negative correlation between polygyny and number of matings by queens, both serving as a possible device to increase colony genetic diversity ${ }^{48}$.

Higher survival for queens producing diploid males in Solenopsis invicta polygynous colonies ${ }^{51}$
Ecology of many polygynous species suggests that they are not particularly likely to lose queens.

No evidence whether shorter lifespan of polygynous queens is a cause or a consequence of polygyny ${ }^{5}$.

Cost of dispersal is extremely difficult to quantify 3,22 so that there are few rigorous tests of the role of ecological constraints on the evolution of polygyny.

The loss of the ability by queens of some polygynous species to initiate a new colony without the help of workers might be a secondary consequence of queens being reaccepted into established colonies.

No positive association between the frequency of polygyny and parasitism across population of Leptothorax longispinosus ${ }^{43}$.

No evidence in other ant species ${ }^{26}$.

Intraspecific parasitism may possibly select for increased queen number in polygynous colonies but is unlikely to account for the evolution of polygyny. Unfortunately, there is currently no data on the frequency of foreign queens infiltrating nests, and thus no way to test this hypothesis.

Unlikely that evolution of polygyny results from benefits of increased genetic diversity per se ${ }^{48}$

No evidence that increased genetic diversity increases colony productivity or disease resistance ${ }^{49.50}$.

High proportion of queens producing diploid males, as in $S$. invicta, is uncommon (caused by a recent bottleneck ${ }^{52}$ ).

No evidence of a strong link between polygyny and production of diploid males in other ant species ${ }^{53}$

\section{Other hypotheses}

Queen parasitism ${ }^{54}$. Polygyne queens are intraspecific parasites. They raise their fitness at the expense of the other colony members.

Phylogenetic constraints 55
Inter-nest variation in queen number in some number of parasites on their host ${ }^{54}$.

Queen number is fixed in many wasp and bee taxa55. Myrmica species mimics distribution of the
Not consistent with queens being mostly recruited from their own nest.
Queen number is extremely labile in ants ${ }^{55}$ dispersal habits. Monogyny typically is associated with colony reproduction by the emission of sexuals, mating away from the nest following flight, solitary colony foundation and wide dispersal. In contrast, polygyny often coincides with a loss of the mating flight, mating occurring in or near the nest, and colonies reproducing through budding, a process in which queens leave their nest with workers to initiate a new nest in close proximity $7,12,27,28$. These differences in reproductive strategies are associated with particular queen phenotypes. Monogynous queens tend to have larger body size and energy reserves than their polygynous counterparts ${ }^{29,30}$. Thus, the shift from a single to many queens per colony in ants is associated with a profound shift in several facets of the social biology that constitute, in effect, a polygyny syndrome ${ }^{12}$.

These differences in reproductive patterns, dispersal habits and reproductive phenotypes associated with variation in queen number support the hypothesis that ecological constraints on independent colony founding are a major factor selecting for polygyny. When suitable nest sites are located relatively close to each other and independent founding is risky and/or nest sites are limited, reproduction through budding is an effective means of dispersal, since queens are accompanied by workers that can protect them efficiently. Queens accompanied by workers are also likely to outcompete single queens for available sites. Thus, decreased success of independent founding will select simultaneously for polygyny and reproduction through budding ${ }^{15}$. (If reproduction through budding is advantageous this may also indirectly select for polygyny since the presence of several queens is required for this mode of reproduction.) None of the other hypotheses explains the association between queen number and mode of colony founding. High cost of dispersal not only favours colony reproduction through budding, but also selects for higher colony survivorship. This is because a low probability of successful colony founding increases the relative value of an established colony ${ }^{15}$. Thus, when the cost of dispersal is high, colonies should 
invest proportionally more in colony maintenance (worker production $)^{31}$ and should also favour the presence of several related queens to reduce the risk of colony extinction following queen loss (or death).

In conclusion, risky dispersal is most likely a key factor selecting for polygyny in ants. However, several other factors, such as a high probability of colonies losing their queens and a queen lifespan that is brief in relation to colony survivorship, probably work in concert, lowering the threshold beyond which colonies benefit by reaccepting queens. These two categories of factors (ecological constraints on dispersal and in trinsic benefits of having multiple queens through increased colony survival) are the counterparts of the 'ecological constraints' and 'benefits of philopatry' components of models proposed to account for the evolution of cooperative breeding in birds. As Emlen ${ }^{20}$ pointed out, these two types of factors are in fact complementary since 'having poor option for independent breeding is part and parcel of what makes a good situation at home, and vice versa'. Similarly, the costs and benefits for colony members of reaccepting young queens depend on the nature of the alternative reproductive options for these queens outside the mother colony.

Other hypotheses listed in Table 1 may also play some role, but they are probably of lesser importance. A qualification of all the hypotheses assuming an advantage to members of established colonies is that queens are recruited from within the nest, with the effect that they should be related ${ }^{4}$. Table 2 shows that queens within the same nest are indeed generally related ( 23 species: mean relatedness $=0.35 \pm 0.23$ ). However, there is much interspecific variation in relatedness values, with a few species in which queen-queen relatedness is not significantly different from zero. Why is this so?

\section{Large families and relatedness erosion}

Table 2 shows considerable variation among species in the number of queens per nest, with the average number of queens in polygynous colonies ranging from 2.7 to $>100$. Many species are facultatively polygynous with monogynous and polygynous colonies. Species that have high frequencies of monogynous colonies generally have polygynous colonies containing relatively few queens. In contrast, species in which monogynous colonies are rare frequently have high numbers of queens in polygynous colonies (e.g. Refs 32-36). The degree of polygyny spans a continuum from, at one end, species with a low frequency of polygynous colonies and low queen numbers in polygynous colonies to, at the other end, species in which colonies are always polygynous and contain high numbers of queens.

As with queen number, there is also much variation in relatedness among nestmate queens, the values ranging from zero to 0.83 (a value not significantly different from 


\section{Box 1. The ecology of polygyny}

Several lines of evidence support the hypothesis that the evolution of colonies with many queens may be associated with extremely risky dispersal.

First, intraspecific comparisons suggest that the size of young queens and their fat resenves (an important factor influencing the success of independent colony-founding queens ${ }^{29}$ ) is inversely correlated with the number of reproductive queens per colony in several ant species 66,67 , suggesting that high queen number might be associated with reduced dispersal capabilities of queens $66-68$

Second, the evolution of colonies with many queens in the genus formica appears frequently to be associated with habitat saturation and reduced success of colony founding ${ }^{10}$.

Finally, many species with high queen numbers have evolved a particular type of social organization in which there is extensive intermixing of queens and workers between nests (so-called unicolonial populations). In such species, colony boundaries are virtuaily abolished 7,9,30 and colonies live in empty or disturbed habitats in which several of their characteristics, such as rapid colony budding, large numbers of workers and queens per nest and a generalist diet, favour rapid expansion. The absence of inter-nest aggression combined with colony reproduction generally allows these species to monopolize entire patches of habitat and to exclude virtually all other ant species. Their capacity to monopolize a habitat contrasts with the poor colonization abilities of young queens in these species. For example, it has been suggested that only once per tens or hundreds of generations of sexual brood can a single young queen succeed in founding a new colony in some Formica ants when the habitat is saturated ${ }^{10.15}$. Recent genetic data indeed showed that several highly polygynous Formica and Myrmica species are characterized by a significant population structuring; in contrast, no significant population viscosity was detected in closely related species or populations that were monogynous or had colonies with low queen numbers ${ }^{57,69}$.

ship between queen number and queen-queen relatedness $\left(\mathrm{r}_{\mathrm{s}}=-0.66 ; \quad Z=-3.99\right.$ $n=38 ; P<0.001)$ across the 38 populations for which data on queen-queen relatedness and queen number have been documented (L. Keller, unpublished). Similarly, the same trend occurs among populations of the ant $M$. rubra, with a negative correlation $\left(r_{\mathrm{s}}=-0.73 ; Z=-2.42\right.$ $n=12 ; P<0.02)$ between queenqueen relatedness and queen number (L. Keller, unpublished). Insufficient numbers of populations have been studied in other species to conduct similar intraspecific comparison. Finally, queen-

0.75 , the expected value if queens are full sisters). Nonacs ${ }^{5}$ and Pamilo ${ }^{6}$ suggested that low queen-queen relatedness may stem from the recruitment of queens over several generations and outbreeding. Relatedness among queens equals $3 /(3 n+1)$ in a colony containing $n$ queens when queen number remains constant over time and colonies recruit new queens from their own daughters ${ }^{6}$. For instance, the expected queen-queen relatedness is 0.05 in a colony with 20 queens. Several other factors, such as temporal variation in queen number, high variance among colonies in queen number, number of matings per queen and differences in the relative contribution of queens to reproduction will affect withinnest relatedness (e.g. Refs 34,37). However, the important point is that the low relatedness among queens does not necessarily imply recruitment of a high proportion of queens from other nests when colonies contain many queens.

Available data are indeed consistent with the hypothesis that colonies recruit mostly nestmate queens over several generations, thus leading to low queen-queen relatedness when colony queen number is high. Relatedness among queens is significantly negatively correlated with the number of queens per nest (Spearman rank correlation, 16 species $\mathrm{r}_{\mathrm{s}}=-0.68 ; Z=-2.65 ; P<0.01$; I used an average of 30 , 100 and 20 queens for Formica trunconum, Linepithema humile and Myrmica galieni, respectively). An analysis at the population level also reveals a significant negative relation- queen relatedness correlates with worker-worker relatedness both at the species $\left(r_{s}=0.77 ; Z=3.49 ; n=23 ; P<0.001\right)$ and population levels $\left(r_{\mathrm{s}}=0.69 ; Z=4.46 ; n=43 ; P<0.001\right.$, L. Keller, unpublished), a result also consistent with the hypothesis that colonies mostly recruit queens from within their colony. Thus, low relatedness among nestmate queens may be accounted for when colonies contain many queens that are recruited over several generations. The question is, thus, why do colonies reaccept so many queens?

A striking feature of species with high queen number is that queens often have partly or completely lost the ability to establish new colonies independently (without the help of workers). For instance, fire ant (Solenopsis invicta) queens from polygynous colonies almost never succeed in founding new colonies independently ${ }^{28}$. Argentine ant (Linepithema humile $=$ Iridomyrmex humilis) queens have completely lost this ability ${ }^{29}$. Complete loss of a queen's ability to establish colonies independently seems to be common in species with high queen numbers, but rare in polygynous species containing few queens ${ }^{30}$. The loss of the competence of queens to initiate new colonies independently probably originated from the extremely low success of independent founding, further suggesting that the evolution of colonies with many queens may be associated with extremely risky dispersal. Ecological features of many species characterized by high queen number support this hypothesis (Box 1).

In conclusion, high queen number per colony probably frequently arises from (1) extreme constraints on colony founding with strong selection on young queens to seek readoption into established colonies, and (2) colonies more likely to reaccept daughter queens. Such conditions may result in recruitment of queens over several generations and thus lead to low within-nest relatedness. Moreover, because colony reproduction virtually always occurs through budding, within-nest relatedness may always be low so that the recruited queens are not 
less related to colony members than the queens actually present in a colony. Finally, Pamilo ${ }^{6}$ also showed that the effect of the addition of new queens on the fitness of colony members decreases with higher queen number so that there is weak selection against increased polygyny when queen number is high. Because of the combined effects of these factors, the evolution of colonies with high queen number may thus not be as challenging to kin selection as it seems at first sight. However, low within-nest relatedness raises the question of what selective forces maintain worker reproductive altruism. As discussed in Box 2, it seems that obligate worker sterility and worker control over caste determination might, in fact, be important factors required for colonies with low within-colony relatedness to be evolutionary stable. Under such conditions, individuals that are 'trapped' in the worker phenotype have no other option than helping.

\section{To reproduce or not to reproduce}

There is tremendous interspecific variation in the reproductive output of nestmate queens, with queens of some species sharing reproduction relatively equally, whereas in others a single queen is able to monopolize reproduction ${ }^{3,23,24}$ In a remarkable paper, Bourke and Heinze ${ }^{26}$ investigated the factors underlying variation in reproduction among nestmate queens in the tribe Leptothoracini, a group particularly suitable for such studies because of the extreme diversity of social organization. The magnitude of reproductive skew is predicted to increase with increasing ecological constraints on independent breeding, because subordinates can expect only small payoffs for leaving if ecological conditions are harsh. Reproductive skew is also predicted to increase with increased relatedness among queens because subordinates that are more closely related to dominants automatically receive larger kin-selective benefits for cooperating peacefully with dominants; hence, they require smaller direct reproductive inducements for such cooperation $17,18,22-24$. As predicted by the models, the degree of reproductive skew in leptothoracine ants increases with greater ecological constraints on dispersal ${ }^{26}$. Available data on partitioning of reproduction of other social insects and mammals and birds are also consistent with the predictions from the skew models ${ }^{21,38-10}$, demonstrating that ecological factors together with internal factors such as relatedness jointly shape reproductive division of labour.

\section{Ants, birds, mammals and social life}

Ecological constraints on independent founding are a key factor selecting for polygyny. Because factors such as cost of dispersal, habitat patchiness and availability of nest sites are notoriously hard to quantify (e.g. Refs 3,22 ), it is not surprising that many of the earlier attempts to identify ecological factors promoting polygyny have proved difficult ${ }^{7,8}$. This problem is well illustrated by the fact that very few studies have been successful at identifying ecological factors associated with the evolution of sociality in vertebrates and insects, although ecological constraints on independent breeding are also likely to be key factors favouring eusociality (e.g. Refs 19-24,40).

That ecological constraints favour simultaneously the evolution of polygyny and sociality illustrates the fact that investigations into the origin and evolution of polygyny and eusociality are complementary. For instance, habitat saturation is most likely the underlying cause selecting for helping behaviour in the Seychelles warbler, Acrocephalus sechellensis ${ }^{40}$, and the evolution of polygyny in the ant Leptothorax longispinosus ${ }^{14}$. In both cases, individuals are selected to remain at home because dispersal is very risky, and they are accepted either because they provide some direct benefit or because their kin have a stake in their survival.

An interesting prediction arising from the hypothesis that ecological constraints and habitat saturation are important factors selecting for polygyny is that there should be fewer polygynous colonies and fewer queens per nest in an early stage following colonization of new habitats by polygynous ants ${ }^{41}$. Once all suitable nestsites have been colonized, one would predict an increase in both the number of polygynous nests and number of queens per nest, and perhaps a decrease in relatedness among nestmate queens. Several species of Formica, Myrmica and Solenopsis with variable numbers of queens per colony would be ideal for such studies. Such comparisons are akin to Komdeur's ${ }^{40}$ pioneering work demonstrating that Seychelles warblers became independent breeders once they had been released into an unoccupied island containing many good breeding territories. However, as the new population increased and all the high-quality habitat became occupled, the young again began to remain at home where they acted as helpers, as they usually do in their native habitat in which breeding vacancies are rare.

Finally, an important message is that the same conceptual framework can be used to study the social organization of insect and vertebrate societies. Ecological factors, together with internal factors, such as relatedness, determine the degree of within-group conflict, partitioning of reproduction and the stable social structure of animals, independently of whether they are ants ${ }^{26}$, birds ${ }^{17,20,21}$ or mammals $\mathbf{s}^{30}$. The time for two research traditions to proceed independently in seeking explanations for the evolution of groupliving and eusociality in insects and vertebrates is over.

\section{Acknowledgements}

I thank Koos Boomsma, Jay Evans, Joan Herbers, Jes Pedersen, Kenneth Ross and Perttu Seppä for providing unpublished data and Koos Boomsma, Andrew Bourke, Giorgina Bernasconi, Michel Chapuisat, Sally Corbet, Philippe Christe, Joan Herbers, Jürgen Heinze, Peter Nonacs, Pekka Pamilo, Francis Ratnieks, Dave Queller, Liselotte Sundström, Edward Vargo and an anonymous referee for comments on the manuscript. This work was funded by the Swiss National Science Foundation (grants no. 31-35584.92, 31-36907.93 and 31-40828.94).

\section{References}

1 Rissing, S.W. and Pollock, G.B. (1988) in Interindividual Behavioral Variability in Social Insects (Jeanne, R.L., ed.), pp. 179-222, Westview Press

2 Keller, L., ed. (1993) Queen Number and Sociality in Insects, Oxford University Press

3 Keller, L. and Vargo, F.I. (1993) in Queen Number and Sociality in Insects (Keller, L., ed.), pp. 16-44, Oxford University Press

4 Pamilo, P. and Rosengren, R. (1984) Biol. J. Linn. Soc. 21, 332-348

5 Nonacs, P. (1988) Evolution 42, 566-582

6 Pamilo, P. (1991) Am. Nat. 138, 412-433

7 Bourke, A.F.G. and Franks, N.R (1995) Social Evolution in Ants, Princeton University Press

8 Herbers, J.M. (1993) in Queen Number and Sociality in Insects (Keller, L., ed.), pp. 262-293, Oxford University Press

9 Hölldobler, B. and Wilson, E.O. (1990) The Ant, Springer-Verlag

10 Rosengren, R., Sundström, L. and Fortelius, W. (1993) in Queen Number and Sociality in Insects (Keller, L., ed.), pp. 308-333, Oxford University Press

11 Hamilton, W.D. (1964) J. Theor. Biol. 7, 1-52

12 Keller, L. (1993) Oikos 67, 177-182

13 Crozier, R.H. (1979) in Social Insects (Vol. 1) (llerman, II.R., ed.), pp. 223-286, Academic Press

14 Herbers, J.M. (1986) Behav. Ecol. Sociobiol. 19, 115-122 
15 Nonacs, P. (1993) in Queen Number and Sociality in Insects (Keller, L., ed.), pp. 110-131, Oxford University Press

16 Heinze, J. (1993) Oecologia 96, 32-39

17 Emlen, S.T. (1982) Am. Nat. 119, 40-53

18 Vehrencamp, S.L. (1983) Anim. Behav. 31, 667-682

19 Emlen, S.T. (1991) in Behavioural Ecology: An Evolutionary Approach (Krebs, J.R. and Davies, N.B., eds), pp. 295-337, Blackwell

20 Emlen, S.T. (1994) Trends Ecol. Evol. 9, 282-285

21 Koenig, W.D., Pitelka, F.A., Carmen, W.J., Mumme, R.L. and Stanback, M.T. (1992) Q. Rev. Biol. 67, 111-150

22 Reeve, H.K. (1991) in The Social Biology of Wasps (Ross, K.G. and Matthews, R.W., eds), pp. 99-148, Cornell University Press

23 Reeve, H.K and Ratnieks, F.L.W. (1993) in Queen Number and Sociality in Insects (Keller, L., ed.), pp. 45-85, Oxford University Press

24 Keller, L. and Reeve, H.K. (1994) Trends Ecol. Evol. 9, 98-102

25 Seger, J. (1993) in Queen Number and Sociality in Insects (Keller, L., ed.), pp. 1-15, Oxford University Press

26 Bourke, A.F.G. and Heinze, J. (1994) Philos. Trans. R. Soc. London Ser. B 345, 359-372

27 Hölldobler, B. and Wilson, E.O. (1977) Naturwissenschaften 64, 8-15

28 Ross, K.G. and Keller, L. Annu. Rev. Ecol. Syst. (in press)

29 Keller, L. and Passera, L. (1989) Oecologia 82, 236-240

30 Passera, L. (1994) Exotic Ants, Biology, Impact, and Control of Introduced Species (Williams, D.F., ed.), pp. 23-43, Westview Press

31 Pamilo, P. (1991) Am. Nat. 137, 83-107

32 Stille, B., Stille, M. and Douwes, P. (1991) Behav. Ecol. Sociobiol. 28, 91-96

33 Pearson, B. and Raybould, A.F. (1993) Sociobiology 21, 209-216

34 Ross, K.G. (1993) Am. Nat. 141, 554-576

35 Seppä, P. (1994) J. Evol. Biol. 7, 71-95

36 Elmes, G. and Keller, L. (1993) in Queen Number and Sociality in Insects (Keller, L., ed.), pp. 294-307, Oxford University Press

37 Queller, D.C. (1993) in Queen Number and Sociality in Insects (Keller, L., ed.), pp. 132-252, Oxford University Press

38 Creel, S.R. and Waser, P.M. (1991) Behav. Ecol. 2, 7-15

39 Reeve, H.K. and Keller, L. (1995) Am. Nat. 145, 119-132

40 Komdeur, J. (1992) Nature 358, 493-495

41 Seppä, P., Sundström, L. and Punttila, P. Biol. J. Linn. Soc. (in press)

42 Ward, P.S. (1983) Behav. Ecol. Sociobiol. 12, 301-307

43 Herbers, J.M. (1986) J. Kans. Entomol. Soc. 59, 675-686

44 Buschinger, A. (1986) Trends Ecol. Evol. 1, 155-160
45 Stille, B. and Stille, M. (1991) Insectes Soc. 39, 335-340

46 Crozier, R.H. and Page, R.E. (1985) Behav. Ecol. Sociobiol. 18 105-115

47 Shykoff, J.A. and Schmid-Hempel, P. (1991) Behav. Ecol. Sociobiol $243,55-58$

48 Keller, L. and Reeve, H.K. (1994) Evolution 38, 694-704

49 Herbers, J.M. (1982) in The Biology of Social Insects (Breed, M.D, Michener, C.D. and Evans, E.H., eds), pp. 238-242, Westview Press

50 Oldroyd, B.P., Rinderer, T.E., Harbo, J.R. and Buco, S.M. (1992) Ann. Entomol. Soc. Am. 85, 335-343

51 Ross, K.G. and Fletcher, D.J.C. (1986) Behav. Ecol. Sociobiol. 19, 283-291

52 Ross, K.G., Vargo, E.L., Keller, L. and Trager, J.C. (1993) Genetics 135, 843-854

53 Pamilo, P., Sundström, L., Fortelius, W. and Rosengren, R. (1994) Ethol. Ecol. Evol. 6, 221-235

54 Elmes, G.W. (1973) J. Anim. Ecol. 42, 761-771

55 Ross, K.G. and Carpenter, J.M. (1991) J. Evol. Biol. 1, 117-130

56 Pamilo, P. (1982) Hereditas 48, 95-106

57 Sundström, L. (1993) Behav. Ecol. Sociobiol. 33, 345-354

58 Boomsma, J.J., Brouwer, A.H. and Van Loon, A.J. (1990) Insectes Soc. $37,363-375$

59 Kaufmann, B., Boomsma, J.J., Passera, L. and Petersens, K.N. (1992) Insectes Soc. 39, 195-200

60 Douwes, P., Sivusaari, L., Noklasson, M. and Stille, B. (1987) Genetica $75,23-29$

61 Heinze, J., Lipski, N., Hölldobler, B. and Bourke, A.F.G. (1995) Zoology 98, 127-135

62 Herbers, J.M. and Grieco, S. (1994) J. Evol Biol 7, 581-598

63 Craig, R. and Crozier, R.H. (1979) Evolution 33, 33.5-341

64 Banschbach, V.S. and Herbers, J.M. Evolution (in press)

65 Pedersen, J.S. and Boomsma, J.J. (1994) Hereditas 121, 221-222

66 Keller, L. and Ross, K.G. (1993) Behav. Ecol. Sociobiol. 33, 121-129

67 Keller, L. and Ross, K.G. (1993) Science 260, 1107-1110

68 Sundström, L. (1995) Behav. Ecol, 6, 132-139

69 Seppä, P. and Pamilo, P. (1995) Heredity 74, 200-209

70 Bourke, A.F.G. (1988) Q. Rev. Biol. 63, 291-311

71 Nonacs, P. (1992) in Evolution and Diversity of Sex Ratio in Insects and Mites (Wrensch, D.L. and Ebberts, M., eds), pp. 384-401, Chapman \& Hall

72 Vargo, E.L. and Passera, L. (1991) Behav. Ecol. Sociobiol. 28, 161-169

73 Nonacs, P. and Tobin, J. (1992) Evolution 46, 1605-1620

\section{Trends in Ecology \& Evolution editorial policy}

Trends in Ecology \& Evolution (TREE) is a current-awareness magazine publishing news, reviews and comment on research activity at the front of ecology and evolutionary biology. It is not a journal for the publication of original results, hypotheses, syntheses or meta-analyses. TREE's authors are encouraged to perceive their role as reporters, chroniclers and commentators, rather than using TREE as a vehicle to publish their own work in a different format.

News \& Comment articles report on specific new developments published in the primary literature; they also cover conferences. The former, but not the latter, are usually peer reviewed. Reviews chronicle recent progress in particular areas of research. Reviews and Perspectives essays are always peer reviewed.

Articles in TREE are commissioned by the Editor. Manuscripts may nevertheless be rejected by the peer and editorial review process: commissioning does not guarantee publication. 